\title{
Allocation of Costs for Electronic Products in Academic Library Consortia
}

\author{
Douglas Anderson
}

\begin{abstract}
As the prevalence of consortial licenses for electronic products increases, consortia face decisions about how to allocate costs for these products among participating libraries. Although there are a number of possible formulae for this, some are problematic in that they result in inequitable cost allocations in certain circumstances. Several methods for apportioning costs within consortia are discussed, including equal division by institution and proportional division by institutional FTE, as well as a combination of these. Other methods evaluated include proportional distribution of cost savings, a method utilizing bids, and usage-based distributions.
\end{abstract}

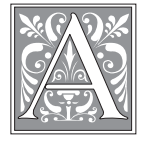

s budgetary pressures have become endemic in the world of academic libraries, library administrators have become increasingly ingenious in finding ways to stretch their funds. These pressures arise from the combination of decreasing or flat institutional funding for their acquisitions, inflating costs for continuations, and generally high costs for a burgeoning array of new electronic resources. ${ }^{1}$ One approach they have taken with licensing electronic resources is to explore the possibilities of consortial subscriptions with vendors of these products. And as vendors have shown themselves willing to offer consortial discounts for their products, libraries have frequently made use of consortial relationships formed previously and for other reasons to reduce their costs. In addition, numerous other consortia have been formed specifically for the purpose of licensing electronic products, some based on centralized external funding and others based on funding pooled or assessed from the participating libraries. Indeed, some consortia have been formed on quite ad hoc bases expressly for the purpose of licensing specific electronic products. ${ }^{2}$

Not all vendors have been willing to deal with consortia, but others have recognized its advantages. Some vendors have been motivated to offer consortial discounts because they expect such arrangements to result in reduced opera-

Douglas Anderson is Director of the Library at Marietta College in Ohio; e-mail: doug.anderson@marietta. edu. An Excel spreadsheet containing the examples in this article can be accessed from <http://www.marietta. edu/ nda001/consortial>. The author gratefully acknowledges the influence on the ideas developed here of colleagues in several consortia, including the Associated Colleges of the South (ACS), the South Carolina Independent Colleges and Universities (SCICU), and the Partnership among South Carolina Academic Libraries (PASCAL). In addition, the author offers his thanks to Mary Bull of the South Carolina State Library, Sue Medina of the Network of Alabama Academic Libraries (NAAL), and Britannica Online for the assistance they provided. 
tional costs. This expectation of reduced costs for the vendor comes about from the assumption that the consortium will assume certain responsibilities, such as billing individual libraries or providing basic technical support and training. ${ }^{3}$ Other vendors have seen consortia merely as another sort of marketing mechanism and have expected to gain increased revenues from libraries that might not have subscribed to their products otherwise. ${ }^{4}$ Viewing this situation from the perspective of an economist, one could say that consortial pricing is an example of a pricing strategy that enables vendors to maximize their revenues by averaging out the different valuations that libraries place on the products they produce. ${ }^{5}$

Even when vendors do not offer specific discounting for consortia, there are other possibilities for cost savings. With vendors who price their products based on a limited number of concurrent or simultaneous user licenses, consortia can achieve savings by accessing a common pool of user licenses and contending for a smaller number of licenses (sometimes referred to as "ports," from the earlier technology of terminal-based connections to servers) than they would require individually. ${ }^{6}$ Because searching sessions on these remote resources tend to be random, but with predictable frequency throughout the day, contending for available licenses across a consortium can be a very effective strategy. Some vendors that license their products this way report turn-aways, peak simultaneous users, and other usage statistics that facilitate the fine tuning of the number of concurrent licenses required for the consortial license. $^{7}$

Consortial licenses are becoming so common that one may wonder whether consortial pricing is becoming the new base line for vendors' product pricing. Libraries that continue to purchase products without the benefit of consortial involvement may be paying a premium for that privilege. This viewpoint is echoed in the observation that "if you don't find a way to join a consortium, then the dynamics of your buying power remain the same while everyone else's increase.... Individual libraries are not going to keep up." ${ }^{\prime 8}$

When consortia are not based on a centralized funding source, they face the challenge of deciding how to allocate the costs of the products to which they subscribe among their member libraries. This article examines several formulae for the allocation of costs within consortia. For the purposes of this study, two hypothetical consortia are used. Consortium A is a fairly homogeneous consortium of libraries associated with institutions of approximately the same size. Consortium $B$ is a rather heterogeneous consortium of libraries associated with institutions of widely different size.

It has been observed that "consortia best serve libraries of a similar type, with similar goals and objectives." ${ }^{9}$ Similarly most of the methods described below for allocating costs within consortia are applicable only to libraries of the same type. For this reason, discussion is limited to academic libraries and examples drawn relevant to them. Some of the techniques may be generalized and applied to other single-type consortia, such as public libraries, but application to multitype consortia is likely to be very problematic.

\section{Two Simple Methods}

Perhaps the easiest method for allocating the costs to member libraries of a consortium is to divide the costs equally among them. (See table 1, column a.) For consortia with member libraries from institutions of similar size (Consortium A in table 1), this method can work fairly well. Consortia made up of libraries from institutions with more disparate sizes, however, may find this method problematic. (See Consortium B in table 1.)

The strengths and weaknesses of this approach are noticed most clearly in a comparison of the \%/FTE and \%/Cost columns of table 1 . The greater difference between the size of the institution relative to the others in the consortium (repre- 


\begin{tabular}{|c|c|c|c|c|c|c|}
\hline \multicolumn{7}{|c|}{$\begin{array}{r}\text { TABLE } 1 \\
\text { Two Simple Methods of }\end{array}$} \\
\hline & \multirow[b]{2}{*}{ FTE } & \multirow[b]{2}{*}{$\% /$ FTE } & \multicolumn{2}{|c|}{$\begin{array}{l}\text { a. Equal Division by } \\
\text { Institution }\end{array}$} & \multicolumn{2}{|c|}{$\begin{array}{l}\text { b. Proportional Division } \\
\text { by Institutional FTE } \\
\text { Student Enrollment }\end{array}$} \\
\hline & & & $\begin{array}{c}\text { Allocated } \\
\text { Cost }\end{array}$ & $\% / \operatorname{Cost}$ & $\begin{array}{c}\text { Allocated } \\
\text { Cost }\end{array}$ & $\% /$ Cost \\
\hline \multicolumn{7}{|l|}{ Consortium A } \\
\hline Institution 1 & 6,000 & $24.00 \%$ & $2,000.00$ & $20.00 \%$ & $2,400.00$ & $24.00 \%$ \\
\hline Institution 2 & 5,500 & $22.00 \%$ & $2,000.00$ & $20.00 \%$ & $2,200.00$ & $22.00 \%$ \\
\hline Institution 3 & 5,000 & $20.00 \%$ & $2,000.00$ & $20.00 \%$ & $2,000.00$ & $20.00 \%$ \\
\hline Institution 4 & 4,500 & $18.00 \%$ & $2,000.00$ & $20.00 \%$ & $1,800.00$ & $18.00 \%$ \\
\hline Institution 5 & 4,000 & $16.00 \%$ & $2,000.00$ & $20.00 \%$ & $1,600.00$ & $16.00 \%$ \\
\hline TOTAL & 25,000 & $100.00 \%$ & $10,000.00$ & $100.00 \%$ & $10,000.00$ & $100.00 \%$ \\
\hline \multicolumn{7}{|l|}{ Consortium B } \\
\hline Institution 6 & 15,000 & $44.78 \%$ & $2,000.00$ & $20.00 \%$ & $4,477.61$ & $44.78 \%$ \\
\hline Institution 7 & 10,000 & $29.85 \%$ & $2,000.00$ & $20.00 \%$ & $2,985.07$ & $29.85 \%$ \\
\hline Institution 8 & 5,000 & $14.93 \%$ & $2,000.00$ & $20.00 \%$ & $1,492.54$ & $14.93 \%$ \\
\hline Institution 9 & 2,500 & $7.46 \%$ & $2,000.00$ & $20.00 \%$ & 746.27 & $7.46 \%$ \\
\hline Institution 10 & 1,000 & $2.98 \%$ & $2,000.00$ & $20.00 \%$ & 298.51 & $2.98 \%$ \\
\hline TOTAL & 33,500 & $100.00 \%$ & $10,000.00$ & $100.00 \%$ & $10,000.00$ & $100.00 \%$ \\
\hline
\end{tabular}

sented by \%/FTE) and the portion of the cost borne by that institution (represented by $\% /$ cost), the more that cost allocation scheme will be seen as advantageous or disadvantageous by the institutional participants in the consortium. In general, the larger institutions in the consortium will likely see this method as advantageous and the smaller ones will not. Under this scheme, it may seem intuitively as though the smaller institutions are supporting the larger ones. Compare, for example, Institution 10, which accounts for only about 3 percent of the aggregate enrollment of the consortium but is paying 20 percent of the cost, with Institution 6, which accounts for over 44 percent of the enrollment but is also paying 20 percent of the cost.

Another simple method for allocating the cost for consortial purchases is to divide it proportionally among institutional participants according to size. For consortia that have tried and rejected equal division by institution, this might seem to be a more logical approach. It appears to address directly the issue that would have made equal division seem most problematic, that is, the differences in size of the consortium's libraries or their parent institutions.

A number of measures might be used as a surrogate for size of consortium participants, among them the parent institution's student enrollment or its general budget, the library's materials budget, its total annual circulation, its collection size, or some combination of these factors. Perhaps the most common measure of the size of an educational institution is its fulltime equivalent (FTE) student enrollment. If there is a commonly accepted definition of FTE, the following formula would seem to articulate it.

Full-time Equivalent (FTE) student enrollment is determined by dividing credit hours taken by undergraduate and professional students 
by 15 and by dividing credit hours taken by graduate students by 12 and summing the two quotients. ${ }^{10}$

This definition should be appropriate for institutions with semester calendars and a three-hour course standard. Institutions with other arrangements, such as quarter calendars or other course-hour standards, probably would define FTE somewhat differently in order to provide a reasonable and comparable representation of their enrollment.

Another definition of FTE student enrollment that is becoming prevalent is to sum the number of students enrolled full-time with one-third of the number of students enrolled part-time. This definition is gaining popularity because it has been adopted as part of the Common Data Set standard used by a number of institutions and several publishers who focus on higher education statistics, such as College Board, Thomson Peterson's, and U.S. News \& World Report. ${ }^{11}$ Though it glosses over some finer distinctions, its value is that it provides generally meaningful statistics regardless of the various calendars and course-hour standards to which it is applied. As a result, it can serve as an effective tool for comparing institutions and can be useful in applications such as those under consideration here.

In any case, at most institutions the registrar or office of institutional research has likely already adopted some official definition for FTE. Consortia can require a particular formula in order to be consistent or can accept their member institutions' own standards. For the sake of consistency, though, consortia probably should establish expectations for which programs are to be counted in the statistic. Continuing education, distance education, and other auxiliary programs, for example, may or may not be counted routinely by different institutions. A useful standard for a consortium would be to establish the expectation that member institutions count all students who are able to access the licensed resource.
The allocation of cost for a resource for the two hypothetical consortia using a formula based on the FTE of the member institutions is also a very simple calculation (illustrated in table 1, column b). Like the method dividing the cost equally by institution, this method can work acceptably for consortia with member institutions of similar size, but it is also problematic for more heterogeneous consortia. In some ways, the practical result of proportional division by FTE would be the converse of an equal division by institution. The smaller institutions in the consortium will see this method as advantageous; the larger ones will not. In this case, it may seem as though the larger institutions are supporting the smaller ones, although this is less obviously the case than it is for smaller institutions when the cost is divided equally.

Perhaps the key reason that larger institutions would feel disadvantaged by this approach stems from the fact that vendors commonly discount the prices for their products progressively as the size of the consortium grows. Because larger institutions contribute a greater proportion of the size that is achieving this discount for the consortium, they may quite legitimately expect that their contribution should be reflected in their cost for the product through the consortial purchase.

\section{A More Complex Method}

As a way of mitigating the perceived negative aspects of the two simple methods for allocating costs, consortia can and do make use of a hybrid of the two methods, apportioning some of the cost equally among the institutions and some proportionally by FTE. ${ }^{12}$ Because the results of this method of calculating a cost allocation lie in between the extremes of the first two simpler methods, many consortia would view this method as an good compromise.

Unless some other factor is taken into consideration, though, the distribution 
between the two simpler methods of cost allocation, equal division by institution and proportional division by FTE, is necessarily arbitrary. Table 2 illustrates a distribution with 50 percent of the cost allocated using each of the two methods. Because other distributions can be calculated fairly easily, various scenarios can be examined in a trial-and-error fashion until a solution acceptable to the consortium's members is found.

A comparative graphical presentation of the three methods of allocating costs discussed above reveals some interesting results. Figure 1 illustrates the allocation of cost for a purchase by a ten-institution consortium composed of a combination of the two sample consortia. The observation that the largest and smallest institutions in a consortium are the most affected by the choice of allocation method is inescapable. Equally clear is the observation that, for institutions near the average in size for the consortium, the choices may make rather little difference.

\section{Defining Fairness in the Allocation of Costs}

Libraries consider many factors when evaluating whether to take part in a consortial purchase of an electronic product. Some of those issues, though relevant to the library considering such a situation, are not of particular interest for consideration here. This would include issues internal to the library, such as determining the appropriate expenditure to support a particular subject area. It also would include political issues, such as willingness to participate in a particular consortial arrangement for the good of the organization, even though it might be disadvantageous to a specific library - a sort of consortial altruism.

There are other, more strictly economical issues that are quite pertinent to a general consideration of the suitability of

\begin{tabular}{|l|l|r|r|r|r|}
\hline \multicolumn{7}{|c|}{ TABLE 2 } \\
Combination of Equal Division by Institution and Proportional Division by \\
Institutional FTE Student Enrollment (50/50) \\
\hline \hline \\
\hline
\end{tabular}




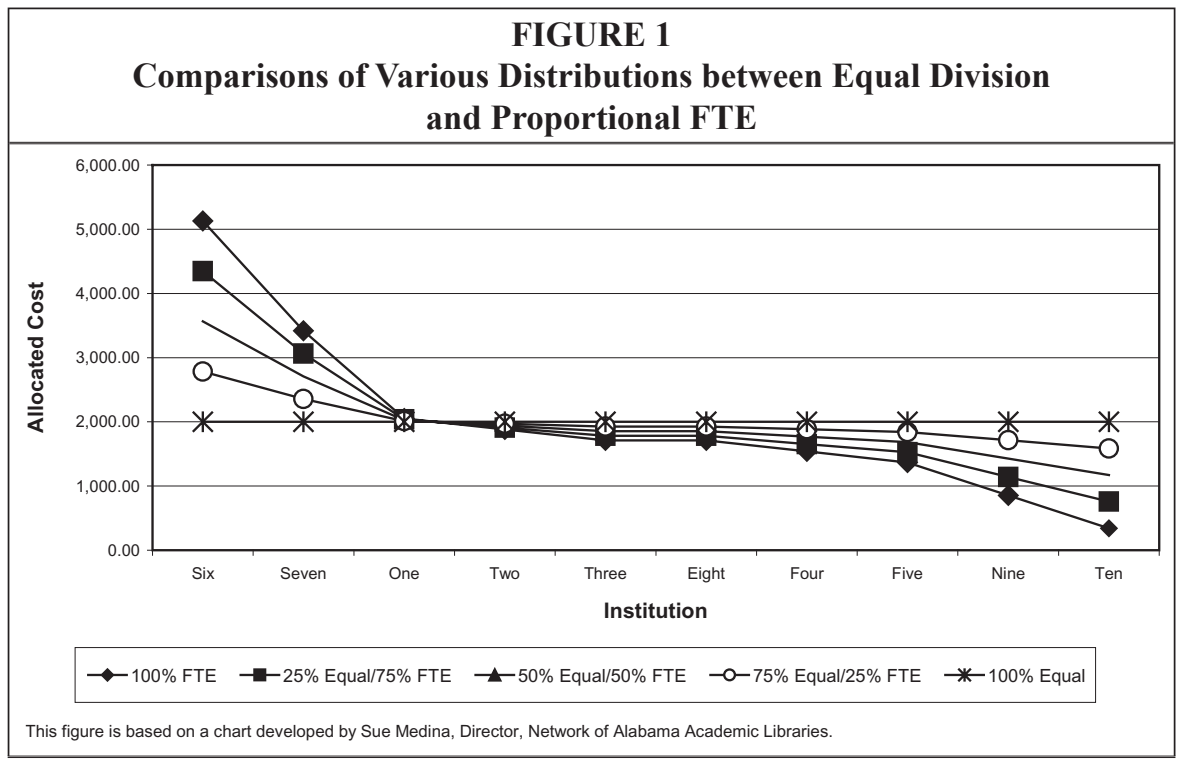

purchasing a particular product through a consortium. These would include knowledge of the pricing for comparable databases, knowledge of the pricing for the same database delivered through another vendor, and even knowledge of the pricing for the very same product licensed for an individual library. Libraries can - and should-consider as much information of this sort as is feasible in order to make an informed decision on whether to subscribe to a product through a particular consortial arrangement.

Another factor that libraries consider in consortial purchases (but one that is rather difficult to quantify) is whether the allocation of costs within the consortium is fair. There is some sense, but perhaps only a theoretical one, in which each of the methods for the dividing of costs described above can be said to be fair because they are all based on formulae that are systematically applied.

Some of the factors that one would consider in describing the notion of fairness in apportioning costs within a consortium are self-evident, including:

- Simplicity and clarity: All participants can understand the method of apportioning costs and are not left with the suspicion that they are being disadvantaged by a complex formula they do not understand.

- Equity and impartiality: All participants feel that they and (perhaps more important) all other participants are paying their fair share of the costs. ${ }^{13}$

Important as they are, these ideas are not sufficient for defining the notion of fairness in a consortial purchase. It must be noted that it is possible for each of the three methods for dividing costs discussed above to generate an allocated cost for an individual library that is higher than the cost would be for that library to subscribe that product without the consortium. This is particularly true of the two simplest methods for dividing costs. Institutions at the extremes, specifically large institutions when dividing costs by FTE and small institutions when dividing costs equally, are most susceptible to this problem. The situation in which one institution is asked to incur additional costs for the sake of the consortium, of course, can destroy the fabric that holds the consortium together. Many consortia recognize this fact and explicitly adopt operating principles that prevent such a situation from developing. ${ }^{14}$ One can 
conclude, then, that the costs that individual libraries would incur if purchasing independently ought to be accounted for in determining a fair allocation of costs within a consortium.

Because individual libraries are likely to consider their potential costs for a given resource from both the individual and consortial point of view, perhaps this should be factored into the notion of what makes for a fair allocation of costs within the consortium itself. This can be done by taking into account how the participants in the consortial license share in the savings achieved by the consortium. It could be argued, in fact, that a consortium's failure to consider the cost savings realized through the consortial arrangement and the effective distribution of those savings among its members can lead to the perception that the allocation of costs in the consortium is unfair. In many ways, fairness is essentially a perception of the participants. ${ }^{15}$ This being the case, because all, or at least many, of the foregoing methods of allocating costs can be said to be equitable and impartial, it may be that the only meaningful measure of fairness is the equitable distribution of cost savings among participants.

\section{Proportionally Distributed Savings}

In some cases, in addition to the cost for a particular product for the consortium, the individual costs for that product for every institution in the consortium are also known. This would be the case, for example, if the vendor's pricing scheme is published. When individual institutions' costs are known, it is a relatively simple calculation to apply the consortial discount equally to each institution in the consortium.

The allocated cost for each institution in table 3 is calculated by determining the percentage discount from the total list price for the discounted consortial price (the Total under Allocated Cost) and then applying that discount to the list price

\begin{tabular}{|c|c|c|c|c|c|c|c|}
\hline \multicolumn{8}{|c|}{$\begin{array}{c}\text { TABLE } 3 \\
\text { Equal Percentage Savings Per Institution }\end{array}$} \\
\hline & FTE & $\% /$ FTE & List Price & $\begin{array}{c}\text { Allocated } \\
\text { Cost }\end{array}$ & $\% /$ Cost & Savings & $\begin{array}{c}\% / \\
\text { Savings }\end{array}$ \\
\hline \multicolumn{8}{|l|}{ Consortium A } \\
\hline Institution 1 & 6,000 & $24.00 \%$ & $4,095.00$ & $3,631.02$ & $23.43 \%$ & 463.98 & $11.33 \%$ \\
\hline Institution 2 & 5,500 & $22.00 \%$ & $3,795.00$ & $3,365.01$ & $21.72 \%$ & 429.99 & $11.33 \%$ \\
\hline Institution 3 & 5,000 & $20.00 \%$ & $3,495.00$ & $3,099.00$ & $20.00 \%$ & 396.00 & $11.33 \%$ \\
\hline Institution 4 & 4,500 & $18.00 \%$ & $3,195.00$ & $2,832.99$ & $18.28 \%$ & 362.01 & $11.33 \%$ \\
\hline Institution 5 & 4,000 & $16.00 \%$ & $2,895.00$ & $2,566.98$ & $16.57 \%$ & 328.02 & $11.33 \%$ \\
\hline TOTAL & 25,000 & $100.00 \%$ & $17,475.00$ & $15,495.00$ & $100.00 \%$ & $1,980.00$ & $11.33 \%$ \\
\hline \multicolumn{8}{|l|}{ Consortium B } \\
\hline Institution 6 & 15,000 & $44.78 \%$ & $9,495.00$ & $8,378.94$ & $42.43 \%$ & $1,116.06$ & $11.75 \%$ \\
\hline Institution 7 & 10,000 & $29.85 \%$ & $6,495.00$ & $5,731.57$ & $29.03 \%$ & 763.43 & $11.75 \%$ \\
\hline Institution 8 & 5,000 & $14.93 \%$ & $3,495.00$ & $3,084.19$ & $15.62 \%$ & 410.81 & $11.75 \%$ \\
\hline Institution 9 & 2,500 & $7.46 \%$ & $1,995.00$ & $1,760.50$ & $8.92 \%$ & 234.50 & $11.75 \%$ \\
\hline Institution 10 & 1,000 & $2.98 \%$ & 895.00 & 789.80 & $4.00 \%$ & 105.20 & $11.75 \%$ \\
\hline TOTAL & 33,500 & $100.00 \%$ & $22,375.00$ & $19,745.00$ & $100.00 \%$ & $2,630.00$ & $11.75 \%$ \\
\hline
\end{tabular}


for each separate institution. As a result, the percentage of savings experienced by each institution in the consortium is identical to that of all the others. Note that the total dollar savings increases for the larger institutions because their proportion of the savings is applied against a larger list price. The slight differences for each institution in table 3 between the percentage of FTE and the percentage of cost can be attributed to the tiered formula used for determining the list price.

Vendors' pricing schemes, such as the one used in this example, frequently give progressive discounts to larger institutions. Thus, a consortium might legitimately give consideration to whether it should, in fact, make it a goal to distribute savings equally. A legitimate point of view would be that this is actually favoring the larger institutions by giving them a disproportionately larger discount because their initial list price (or quoted price) is already more heavily discounted. But a decision not to distribute consortial savings proportionally may lead to a situation that violates the principle that no institution should be asked to pay a consortial price for a particular product that exceeds its cost for purchasing it without the consortium.

\section{Approximated Proportional Savings by Institution}

Some vendors may decline to provide individual pricing for every institution in a consortium. The vendor's rationale for offering discounts to consortia, in fact, may be based on avoiding the overhead of generating numerous, single-institution quotes. But to have some basis on which to make a calculation for the distribution of the savings experienced by the consortium, at least some pricing for individual institutions in the consortium must be known. If a vendor can be persuaded to produce individual quotes for selected institutions in the consortium, it is possible to deduce approximately the extent to which the vendor is basing its pricing on institutional size. By compar- ing quotes for institutions that, at a minimum, represent the larger and smaller in the consortium, the distribution of costs can be interpolated for the remainder of the institutions in order to distribute the savings in a way that approximates a proportional distribution.

Table 4 illustrates the situation in which the list prices for only the largest, smallest, and midsized institutions are known. The allocated cost for each institution is calculated based on a combination of equal division by institution and proportional division by institutional FTE student enrollment. But instead of using an arbitrary distribution between equal division and proportional division, the distribution is optimized to produce the smallest differences, calculated as the standard deviation, in the percentage savings of the institutions for which a list price is known. Several things should be noted about this table. First, the distribution between equal division and proportional division differs between the two hypothetical consortia, 14.16 percent/85.84 percent for Consortium A and 6.07 percent/93.93 percent for Consortium B. ${ }^{16}$ Second, there is some amount of variation in the percentage of savings experienced by the institutions in the consortia. Consortium A in the example can achieve a very similar percentage of savings across the consortium, but Consortium B cannot. The percentage of savings that the institutions in Consortium B experience ranges from 10.01 to 18.61 percent. But all other possibilities of distribution between equal division and proportional division result in even greater disparities. Of course, this is the result of the use of this technique to approximate a proportional distribution of savings to the institutions in the consortium in a situation where only some of the list prices for individual institutions are known.

This illustration assumes that nothing is known about how the vendor's pricing scheme is structured. In some cases, it may be possible to refine the strategy to produce better results. For example, if the vendor uses a tiered pricing scheme, 


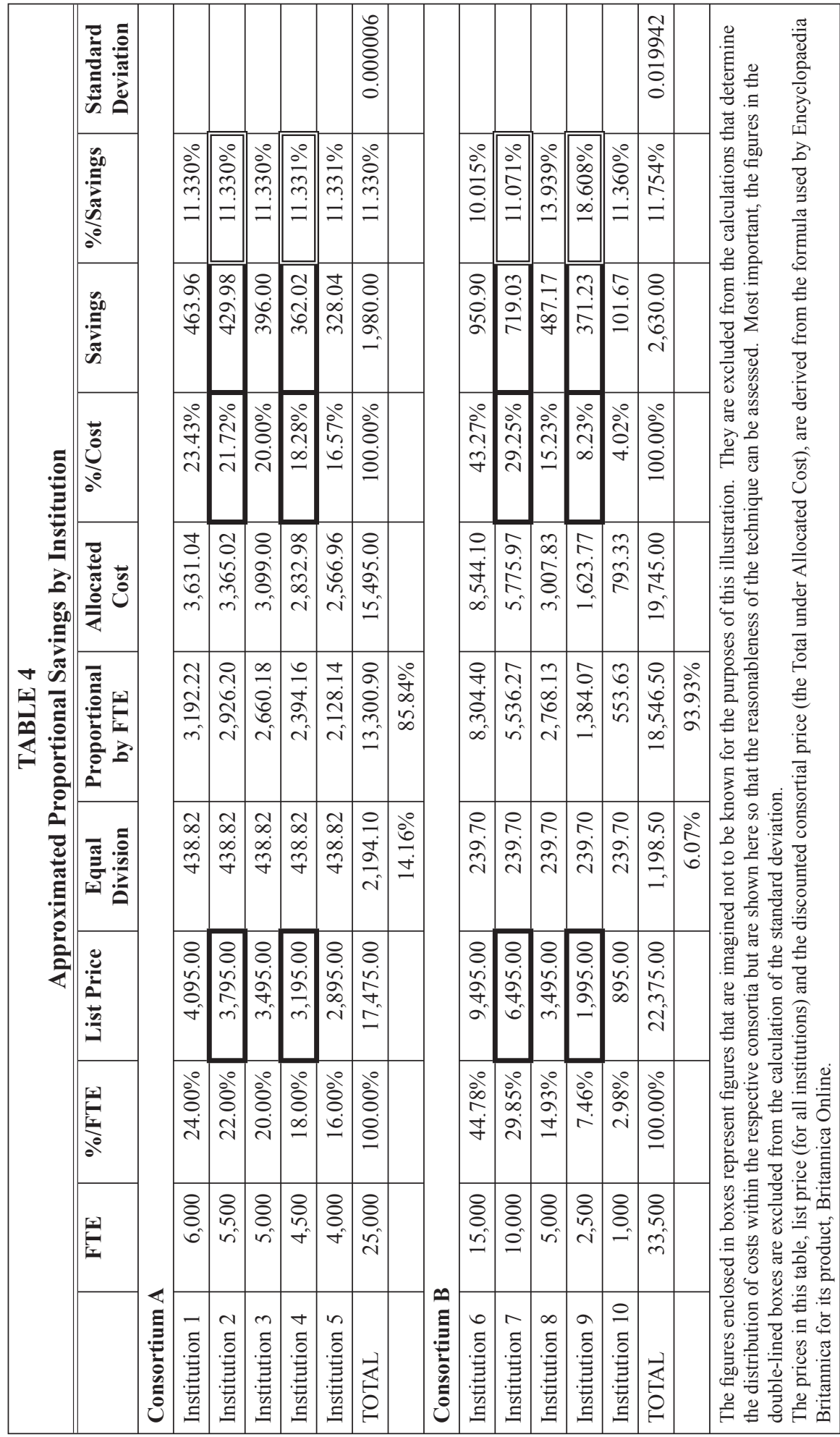


it would be best to select institutions near the middle of their respective categories for sample pricing by the vendor in order to produce the most effective cost allocation across the consortium.

\section{The Bid Method}

Possibly one of the more innovative methods consortia have used to determine how costs for a consortial license will be borne by the participants is one that allows participating libraries to use a bidding process to determine (within limits) what they will pay for a particular resource. Inspired, perhaps, by the popularity of the online auctions such as that of the Web site eBay, this method lets libraries bid as a way to indicate the amount they are willing to pay for a given resource licensed through the consortium. The process described below is used by the Network of Alabama Academic Libraries (NAAL). ${ }^{17}$

After an announcement is distributed to consortium members soliciting expressions of interest in a particular resource and their responses are collated, an initial quote is requested from the vendor. Then a cost analysis is produced and distributed to the group. This analysis illustrates an equal division by institution, a proportional division by FTE, and a 50/50 combination of equal division and proportional by FTE, the consortium's preferred method. The group of potential participants is asked to respond by indicating an amount they are willing to pay to establish the license. If the participants have bid enough to match the quoted amount, the consortium proceeds on those terms. However, if the group has collectively bid too little to begin the license, the institutional bid amounts are distributed to the group as a whole with a comparison to the consortium's preferred method of cost allocation, and the group participants are asked to resubmit their bids. This re-bid process may continue until a solution is found. An institution whose bid is judged to be too low may ultimately be dropped in order to put together a workable license according to NAAL's practices, although in some cases licenses have been initiated with some institutions clearly subsidizing others in order to provide for greater access. In any case, other consortia may choose to adopt their own principles of operation in this regard. If an institution is removed from the process, or if a library voluntarily drops out at this stage, the resource will have to be requoted and the bid process resumed.

For NAAL, the goal in a license established this way is ultimately to move the division of costs toward the formula of a 50/50 combination of equal division and proportional by FTE. In subsequent renewals of the license, for example, if the consortium faces a price increase from the vendor, those paying less than the amount calculated by the preferred method are the first asked to increase their payments.

The principal value of this technique is that it allows a consortium to initiate a license for a resource in the face of unplanned for-and possibly unknownpotential costs. As the consortial license for the resource becomes established, participating institutions can incorporate the necessary funds into their budget planning.

\section{Apportioning Costs Based on Usage}

Most of the methods for allocating costs for consortial purchases discussed above rely on a measure relating to the size of the library or its parent institution. An alternative measure that can be brought into service for determining an allocation of costs, and that would appear to be quite promising, is the relative amount of usage of the licensed product by the participating members of the consortium. Basing a cost allocation on usage would certainly appear to pass the test of fairness in that it would be both simple and impartial.

One drawback to this method, though, is that it is not usable at the beginning of a subscription, there being no usage statistics on which to base an allocation of cost. 
This leads some consortia to consider the adoption of this method beginning in year two of the subscription. ${ }^{18}$ It must be noted that this problem also applies whenever a new institution joins the consortium. Because this method of allocation of costs is applicable only after the subscription has been in place long enough for usage statistics to be available, some other method would have to be adopted in the subscription's first year.

There is another effect of the absence of usage data at the beginning of a subscription. When an institution knows that it will be required to pay for a product in year two based on its usage of the product in year one, it may fear a significant increase in its allocated cost at that time that would force the abrupt cancellation of the resource. So if a usage-based allocation is seen as desirable for a consortium, it may be necessary to phase in this approach over several subscription years. This could be done by first making two alternative allocations, one using usage statistics and the other using one of the foregoing methods of allocating costs, and then gradually shifting the weighting from the latter to the former.

Vendors offer a variety of usage statistics on which consortia can base their allocation strategies. Those probably of most use for this purpose would be the number of search sessions, the number of searches conducted, and the number of full-text documents retrieved or printed. Consortia may choose a combination of these statistical measures in calculating their cost allocations or may use a single measure.

Table 5 illustrates the situation with two hypothetical consortia allocating their costs among participants based on a single measure: the number of searches conducted at the respective institutions in the course of the previous year. The calculation initially determines the percentage of the aggregate searches within the consortia attributed to each institution and then distributes the cost for the subscription among the participants by that percentage.

The search statistics used in table 5 are extrapolated from actual statistics of

\begin{tabular}{|l|r|r|r|r|r|r|}
\hline \multicolumn{7}{|c|}{ TABLE 5 } \\
\hline & \multicolumn{1}{|c|}{ FTE } & \%/FTE & Searches & $\begin{array}{c}\% / \\
\text { Searches }\end{array}$ & $\begin{array}{c}\text { Allocated } \\
\text { Cost }\end{array}$ & \%/Cost \\
\hline \hline Consortium A & & & & \\
\hline Institution 1 & 6,000 & $24.00 \%$ & 225,956 & $27.42 \%$ & $2,742.15$ & $27.42 \%$ \\
\hline Institution 2 & 5,500 & $22.00 \%$ & 47,835 & $5.81 \%$ & 580.51 & $5.81 \%$ \\
\hline Institution 3 & 5,000 & $20.00 \%$ & 401,079 & $48.67 \%$ & $4,867.40$ & $48.67 \%$ \\
\hline Institution 4 & 4,500 & $18.00 \%$ & 58,440 & $7.09 \%$ & 709.21 & $7.09 \%$ \\
\hline Institution 5 & 4,000 & $16.00 \%$ & 90,701 & $11.01 \%$ & $1,100.73$ & $11.01 \%$ \\
\hline TOTAL & 25,000 & $100.00 \%$ & 824,011 & $100.00 \%$ & $10,000.00$ & $100.00 \%$ \\
\hline Consortium B & & & & & \\
\hline Institution 6 & 15,000 & $44.78 \%$ & 412,483 & $46.42 \%$ & $4,641.81$ & $46.42 \%$ \\
\hline Institution 7 & 10,000 & $29.85 \%$ & 283,286 & $31.88 \%$ & $3,187.91$ & $31.88 \%$ \\
\hline Institution 8 & 5,000 & $14.93 \%$ & 107,701 & $12.12 \%$ & $1,212.00$ & $12.12 \%$ \\
\hline Institution 9 & 2,500 & $7.46 \%$ & 29,041 & $3.27 \%$ & 326.81 & $3.27 \%$ \\
\hline Institution 10 & 1,000 & $2.98 \%$ & 56,114 & $6.31 \%$ & 631.47 & $6.31 \%$ \\
\hline TOTAL & 33,500 & $100.00 \%$ & 888,625 & $100.00 \%$ & $10,000.00$ & $100.00 \%$ \\
\hline
\end{tabular}


a real consortium to illustrate the reality of variation that might exist among different institutions. Although the number of searches generally tracks with the size of the institutions, there are some significant anomalies. Noteworthy, for example, is the fact that search statistics for Institution 3 and Institution 8 differ by a factor of four, even though the hypothetical institutions are the same size. In addition, Institution 10 has almost twice as many searches as Institution 9, even though its FTE student enrollment is only 40 percent of the larger institution. Consortia considering allocating their costs based on usage should expect such variability among their participants.

Another potential negative for using usage data in determining cost allocation, and one that has led some consortia explicitly to reject this approach, is that it appears to penalize libraries that have more active instructional programs, engaged faculty who assign library research, and the like. In other words, libraries are disadvantaged when they are more effective in carrying out their mission. ${ }^{19}$ In fact, one could argue that an allocation of costs based on usage results in an economic incentive not to conduct an effective program supporting the use of consortially licensed products. It would be a tragedy indeed if libraries willingly entered into agreements that influenced them negatively in this way. Conversely, it could be argued that this is just the cost of doing business and that, as all consortium participants strive to be more effective, these costs will even out.

A final caveat must be mentioned regarding an allocation of costs based on usage. Like several of the other methods for allocating costs, a usage-based formula has the potential for generating an allocation that would require a library to pay more for the resource through the consortium than it would by purchasing it alone. Arnold Hirshon suggests that this can be remedied by setting a maximum amount of usage an individual library would be assessed. ${ }^{20}$

A usage-based method of allocating costs may be of particular value for consortia with disparate memberships, and especially so for multitype consortia, because it is based on a measure that has an identical meaning for all participating institutions regardless of size or type. Moreover, this method relates the cost of a product for a specific institution directly to the value it gets from the product. Small institutions with research-oriented curricula will likely pay a much higher rate per user using this method because of their higher level of usage. ${ }^{21}$ However, because high-usage institutions are receiving a greater value for their investment, it could be argued that allocating them a higher portion of the costs would be appropriate.

\section{Conclusion}

Academic library consortia have several options when facing decisions on how to allocate costs for their group purchases of electronic products. Each of the various formulae presented here might be appropriate for use in specific situations, although some may be problematic. Consortia should be very sensitive to issues of fairness in the cost-allocation methods they adopt and should take care to implement formulae that are clearly understandable and equitable to all participants.

\section{Notes}

1. Reason Baathuli Nfila and Kwasi Darko-Ampem, "Developments in Academic Library Consortia from the 1960s through to 2000: A Review of the Literature," Library Management 23, no. $4 / 5$ (2002): 209.

2. Barbara Allen and Arnold Hirshon referred to this approach as characterizing a federation more than a consortium and questioned the ability of such an organization to achieve results beyond the most basic. See Barbara McFadden Allen and Arnold Hirshon, "Hanging Together to Avoid Hanging Separately: Opportunities for Academic Libraries and Consortia," Information 


\section{Allocation of Costs for Electronic Products in Academic Library Consortia 135}

Technology and Libraries 17, no. 1 (Mar. 1998): 38.

3. Anthony W. Ferguson, "Consortia mania," Against the Grain 9 (Apr. 1997): 86.

4. Norman Oder, "Consortia Hit Critical Mass," Library Journal 125, no. 2 (Feb. 1, 2000): 50.

5. Andrew Odlyzko, "Competition and Cooperation: Libraries and Publishers in the Transition to Electronic Scholarly Journals" in The Transition from Paper: Where Are We Going and How Will We Get There? ed. R. Stephen Berry and Anne Simon Moffat (Cambridge, Mass.: American Academy of Arts and Sciences, 2001). Available online at http://www.amacad.org/publications/trans13.aspx. [Accessed 14 January 2005].

6. Lindsay Harris and Mary Peterson, "Sharing the Burden: A Model for Consortium Purchasing for Health Libraries," Journal of the Medical Library Association 91, no. 3 (July 2003): 362.

7. These statistical measures are recommended by ICOLC to support consortial licenses for electronic resources. See International Coalition of Library Consortia, "Guidelines for Statistical Measures of Usage of Web-based Information Resources (Update: December 2001)." Available online at http://www.library.yale.edu/consortia/2001webstats.htm. [Accessed 25 November 2004].

8. Tom Sanville, quoted in Ron Feemster, "When Libraries Faced the Future," University Business 3, no. 1 (Feb. 2000): 27.

9. James R. Dwyer, “Consortial Review and Purchase of Networked Resources: The California State University Experience," Bottom Line 12, no. 1 (1999): 10.

10. Indiana University, "Full-time Equivalent Enrollment," Indiana University Fact Book 2004-2005. Available online at http://factbook.indiana.edu/fbook04/enroll/fte.shtml. [Accessed 17 January 2005].

11. Common Data Set Initiative, "Common Data Set 2004-05." Available online at http://www. commondataset.org/cds_200405_v2.pdf. [Accessed 17 January 2005].

12. For a listing of a number of consortia and the factors they take into account when allocating costs, see Bernie Sloan, "Allocating Costs in a Consortial Environment: A Methodology for Library Consortia," OCLC Systems and Services 15, no. 1 (1999): 35-52. Sloan details cost sharing in a number of different types of consortia, including some that are sharing costs for joint operations, such as shared library management systems or document and materials delivery systems, as well as costs for shared licenses for electronic products. 63.

13. Some of these ideas are derived from Harris and Peterson, "Sharing the Burden," 362

14. ORBIS has done so, for example. "The guiding principles, that all participating libraries should benefit and that no library should pay more than it would by purchasing individually, have meant that allocation formulas have varied from service to service." See Sue A. Burkholder, “ORBIS: Grassroots Academic Partnership," OLA Quarterly 5, no. 1 (winter 1999). Available online at http://www.olaweb.org/quarterly/quar4-4/burkholder.shtml. [Accessed 2 November 2004].

15. Arnold Hirshon, "Library Consortium Funding and E-resource Cost-sharing: Goals, Options, and Best Practices." Available online at http://www.gela.org.ge/eifl/files/present/ Arnold\%20Hirshon-paper.doc. [Accessed 14 January 2005].

16. An ancillary observation about this is relevant to the discussion of the technique illustrated in table 3: consortia that arbitrarily select a 50/50 distribution between equal division and proportional division are likely to be using a formula that is biased toward their larger institutions. It is probably the case that a greater share of the savings is being passed on to the larger institutions than to the smaller ones.

17. Sue Medina, director, Network of Alabama Academic Libraries, in discussion with the author, December 13, 2004.

18. Harvey R. Brenneise, "First Steps in Developing a Statewide Digital Health Library in Michigan," Proceedings of the Victorian Association for Library Automation Conference, E-Volving Information Futures, Melbourne, Australia, February 6-8, 20021 (2002). Available online at http://www. vala.org.au/vala2002/2002pdf/13Brneis.pdf. [Accessed 17 January 2005].

19. Medina, discussion with the author.

20. Hirshon, "Library Consortium Funding and E-resource Cost-sharing."

21. This was the case in the South Australian Human Services Libraries Consortium, which felt that this approach addressed a problem with more specialized databases in which certain larger institutions were seen to be subsidizing the smaller ones that made intensive use of these resources. See Lindsay Harris and Mary Peterson, "Sharing the Burden: A Model for Consortium Purchasing for Health Libraries," Journal of the Medical Library Association 91, no. 3 (July 2003): 362-63. 